\title{
Investigating the efficacy of inventory policy implementation in selected state-owned enterprises in the Gauteng province: A qualitative study
}

\begin{tabular}{|c|c|}
\hline $\begin{array}{l}\text { Authors: } \\
\text { Asanda Penny } \\
\text { Musenga F. M } \\
\text { Keith R. Lamb }\end{array}$ & $\begin{array}{l}\text { (D) } \\
\text { wanya }^{1} \text { (1) }\end{array}$ \\
\hline $\begin{array}{l}\text { Affiliations: } \\
{ }^{1} \text { Department } \\
\text { Supply Chain } \\
\text { Management, } \\
\text { Management } \\
\text { Tshwane Univ } \\
\text { Technology, Pr } \\
\text { South Africa }\end{array}$ & $\begin{array}{l}\text { f Marketing, } \\
\text { nd Sport } \\
\text { Faculty of } \\
\text { siences, } \\
\text { rsity of } \\
\text { etoria, }\end{array}$ \\
\hline $\begin{array}{l}\text { Correspondin } \\
\text { Musenga Mpv } \\
\text { francismpwan }\end{array}$ & $\begin{array}{l}\text { author: } \\
\text { lanya, } \\
\text { la@gmail.com }\end{array}$ \\
\hline $\begin{array}{l}\text { Dates: } \\
\text { Received: } 06 \text { N } \\
\text { Accepted: } 19 \\
\text { Published: } 28\end{array}$ & $\begin{array}{l}\text { ov. } 2020 \\
\text { uly } 2021 \\
\text { Pct. } 2021\end{array}$ \\
\hline $\begin{array}{l}\text { How to cite th } \\
\text { Penny, A., Mp } \\
\text { Lambert, K.R., } \\
\text { 'Investigating } \\
\text { inventory poli } \\
\text { implementatic } \\
\text { state-owned } \\
\text { the Gauteng p } \\
\text { qualitative stu } \\
\text { Transport and } \\
\text { Management } \\
\text { https://doi.or } \\
\text { jtscm.v15i0.55 }\end{array}$ & $\begin{array}{l}\text { is article: } \\
\text { vanya, M.F. \& } \\
2021, \\
\text { he efficacy of } \\
y \\
n \text { in selected } \\
\text { nterprises in } \\
\text { ovince: A } \\
\text { dy', Journal of } \\
\text { Supply Chain } \\
15(0), \text { a552. } \\
\text { /10.4102/ } \\
2\end{array}$ \\
\hline $\begin{array}{l}\text { Copyright: } \\
\text { (C) 2021. The A } \\
\text { Licensee: AOS } \\
\text { is licensed unc } \\
\text { Creative Comr } \\
\text { Attribution Lic }\end{array}$ & $\begin{array}{l}\text { uthors. } \\
\text { S. This work } \\
\text { er the } \\
\text { lons } \\
\text { ense. }\end{array}$ \\
\hline Read online: & \\
\hline 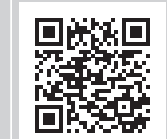 & $\begin{array}{l}\text { Scan this QR } \\
\text { code with your } \\
\text { smart phone or } \\
\text { mobile device } \\
\text { to read online. }\end{array}$ \\
\hline
\end{tabular}

Background: The formulation, implementation and evaluation of inventory policies are vital for adequate management of inventory in organisations to ensure seamless flow of inventory and customer satisfaction. Inventory policies offer the required guidelines on how inventory should be managed in organisations to attain inventory management goals. However, it is unclear whether these guidelines are efficaciously implemented to enhance the inventory management performance of Eskom and Transnet in the Gauteng Province.

Objective: This study sought to investigate the efficacy of inventory policy implementation at each of the selected SOEs in the Gauteng Province.

Method: The study employed a qualitative research design with a sample of twenty-four inventory staff, of which fifteen were from SOE1 and nine from SOE2. The sampled population (inventory staff) were selected purposefully at each SOE in the Gauteng Province. Data were mainly gathered by means of semi-structured interviews and were thematically analysed.

Results: The study generated four themes that reveal the extent of inventory policy implementation and its associated impact on inventory costs at each SOE. These themes included adherence to inventory policy, inventory policy violations, implementation extent of inventory policy, inventory growth rate and the associated increase in inventory carrying costs and lack of inventory planners' planning skills.

Conclusion: Inventory policies were not fully implemented at each SOE. Poor inventory purchasing decision and violation of inventory policies contributed to inventory growth rate and excess inventory carrying and its associated costs. This therefore negatively affects the inventory management performance of SOE 1 and SOE 2.

Keywords: inventory; inventory management; inventory policies; inventory policy implementation; state-owned enterprises; qualitative study.

\section{Introduction}

As a result of increasing competition and cost containment pressure, commercialised organisations, including state-owned enterprises (SOEs), have opted to reengineer their business processes to increase and sustain organisational efficiency and ensure customer satisfaction with a view to remaining in business. Efficient and effective management of inventory is central to this reengineering endeavour in commercialised organisations (e.g. manufacturing, retail and SOEs). One of the ways to achieve this goal and generate saving opportunities for these organisations is the formulation, implementation and evaluation of adequate, efficacious, sector-specific inventory policies.

The fundamental inventory concern relating to 'when and how much to order' is addressed through inventory policy, also known as inventory control systems (Sanders 2012:244). It is argued that organisations that adopt an inventory policy are able to hold the right level of inventory to meet their customers' needs (Lysons \& Farrington 2006:328). Scholars, such as Bowersox, Closs and Cooper (2010:159) and Jalali and Nieuwenhuyse (2015:1217), describe inventory policies as the tools that inform inventory decisions of organisations with respect to what, how much and when to purchase and manufacture. According to Mo, Tseng and Cheung (2014:1296), an inventory replenishment policy guides inventory practitioners on how to 
cautiously handle inventory holding costs whilst maximising service levels.

According to Abdel-Aal et al. (2010:451), inventory policies serve as a control mechanism with respect to the issuing of orders to replenish the stock. Nyabwanga and Ojera (2012:15) considered inventory policies as important tools that give rise to good inventory management performance of organisations. Bowersox et al. (2010:287) claimed that the formulation of a good inventory policy has been empirically proven to be a great inventory management challenge for organisations. Arguably, Mo et al. (2014:1297) stated that well developed inventory policies and effectively implementing them can result in the reduction of inventory carrying costs as inventories are bought, as and when they are needed.

Inventory is defined as the stock of items that are kept on hand by the organisations and are used to meet customer requirements (Abdel-Aal et al. 2010:451; Jacobs \& Chase 2014:515). In the context of the public sector, inventory refers to 'assets which are often held in a warehouse or stockroom with the purpose of distributing the stock to projects to be used for the purpose they were meant for' (South Africa's Department of National Treasury 2009:3). Such projects in the context of SOEs, particularly Eskom and Transnet, include building of substations, rail, port infrastructure, households electrification, amongst others.

Eskom and Transnet, like other SOEs in South Africa hold inventory to achieve their organisational goals. They possess inventory policies aimed to protect and safeguard their inventory investment and guide the inventory staff with respect to inventory control decision making. However, the overall performance of inventory management seems to be, to a greater extent, dependent on how the inventory policies are implemented to meet the customers' needs. This is predicated by the fact that organisations' inventory holding decisions are largely informed by their operational requirements (e.g. customer service levels to meet and the amount of money to be invested in inventory). Poorly implemented inventory policies appear to be at the core of inventory management challenges that many organisations (including SOEs in South Africa) are facing, such as over-stocking or under-stocking and the related costs of these.

It has been highlighted that most public and private entities underperform because of inventory mismanagement (Hanson, Ackah \& Agboyi 2015:86). Eskom and Transnet are not exempt from this challenge, which leads to financial consequences, including loss in revenue, obsolete and damaged inventory, amongst others. However, wellimplemented inventory policies and skilled inventory planners and inventory managers could play a crucial role in improving the inventory management performance of each SOE. Such strategic endeavour would only require the willingness and support of the management of each SOE to implement business mechanisms that can assist in minimising levels and costs of inventory, whilst maximally increasing levels of customer service. These mechanisms should form the basis for the development of inventory policies and should be enforced by consequence management if not implemented accordingly.

According to Stop Stock-out National Survey (2013:12), stock-outs of human immunodeficiency virus (HIV) and tuberculosis drugs constitute a huge life-threatening challenge to patients living with these medical conditions. Similarly, it has been reported on several occasions in the media that South Africa's Department of Health faces shortages in chronic medical products, suggesting understocking of these products. Mensah (2015:v) emphasises how important it is to effectively manage inventory in hospitals as the lives of patients would be at risk if there are shortages in medication. Consistent with this reasoning, the National Treasury states that improved management of inventory in public entities may result in a decrease in inventory holding costs and increase in inventory revenue generation (South Africa's Department of National Treasury 2009:6). This suggests that:

[I]f public servants would apply correct inventory management principles when executing their daily duties, government departments and other public entities would be well positioned to provide enhanced service delivery, such as eradication of stock-outs when it comes to chronic medication provided to those patients who solely rely on government to provide health care. (Penny 2019:22)

Mohubedu (2017:10) investigated inventory management in the electricity industry in South Africa and observed some inventory management inadequacies at Eskom. She recommended that Eskom should investigate the root causes of these inadequacies and establish and implement inventory policies to reduce losses and increase profits. This recommendation is one of the reasons that triggered the investigation into the implementation of inventory policies at Eskom and Transnet to identify and establish whether the implementation of inventory policies enhance the inventory management performance of each of these SOEs. This study argues that full implementation of inventory policies serves as a catalyst for efficient and effective inventory management.

\section{Problem statement}

Inventory policies play a vital role in guiding the inventory decisions in order to attain efficient inventory management in organisations. Fogarty, Blackstone and Hoffmann (1991:157) advised inventory managers to align both their inventory decisions and inventory policies with the overall organisational objectives to ensure efficient management of inventory.

Although Eskom and Transnet have inventory policies to secure their capital investment in inventory, it is unknown 
whether these policies are implemented to protect such investment, prevent incurrence of capital or opportunity costs, maximise customer satisfaction levels, and generate profits.

Literature provides sufficient evidence of a multitude of studies conducted on inventory policy implementation in manufacturing, retail, service and humanitarian settings. Only the recently conducted studies are provided for illustration purposes and similarities to the present study: Singha, Buddhakulsomsiri and Parthanadee (2017); Riza, Purba and Mukhlisin (2018); Paluch (2019); Alim and Beullens (2020) and Panday and Navanti (2021). Despite the unquestionable importance of using inventory policies to ensure efficient inventory management in organisations, assessment of the efficacy of inventory policy implementation in SOEs has not yet received the attention of scholars.

Milondzo and Mashau (2015) conducted a qualitative investigation to explore inventory management accountability and its consequences within Eskom in the Limpopo Province. This investigation revealed that most participants failed to comply with inventory management principles, procedures, standards and norms. Most of the participants who were interviewed also indicated that inefficient inventory management practices within Eskom were caused by various factors. These include lack of appropriate staff training on inventory management, unethical behaviour by managers and officials, inadequate managerial skills, inadequate record keeping skills, poor leadership, lack of culture of accountability at operational level, lack of inventory monitoring and evaluation, and negligence of managers, officials and employees to evaluate the components of inventory management. All these factors impacted negatively on Eskom's organisational performance and this could have been prevented if adequate inventory management policies were implemented and evaluated regularly. Although Milondzo and Mashau (2015)'s findings have revealed non-compliance with inventory management principles, norms and standards and inefficient inventory management practices at Eskom's Limpopo division, surprisingly the efficacy of implemented inventory policies in South Africa's SOEs has not yet been investigated or evaluated. More importantly, the efficacy of inventory policies implemented at Eskom's and Transnet's inventory management divisions in Gauteng remains an unexplored research area. Therefore, the investigative problem is stated as follows: There is a lack of knowledge on the extent of adherence to inventory policies by Eskom's and Transnet's inventory staff working in Gauteng. This may negatively impact the inventory management performance and organisational performance, unless full adherence and/or implementation of inventory policies are enforced.

\section{Research purpose and specific objectives}

The purpose of this study is to investigate the efficacy of inventory policy implementation at each of the selected SOEs in the Gauteng Province. The specific objectives are to:
- Assess the extent to which the established inventory policy of each of the selected SOEs is implemented.

- Evaluate the impact of non-adherence to the inventory policy on inventory costs of each of the selected SOEs.

\section{Literature discussion Inventory and inventory management}

Although inventory is considered to be the lifeblood of manufacturing and retail organisations, it requires enormous investments to operate (Horn et al. 2015:73). It is also an essential or critical asset for service organisations such as hospitals, hotels and hair salons, as these organisations cannot operate without sufficient inventory in the form of medical supplies, soaps in hotel rooms or hair products in hair salons, respectively.

\section{Inventory classification}

Stock and Lambert (2001:233) classify inventories into six different types. These are defined as follows:

- Cycle stock: A cycle stock is an inventory that is generated for refilling purposes and is held to meet certain and predictable customer demand for a product. Under this condition, demand and lead time for products are assumed not to vary.

- In-transit inventories: These are stocks moving from one point to another. This type of inventory may be deemed to be part of the cycle stock even though it is unavailable for sale, use or delivery until it reaches its destination.

- Safety or buffer stock: A safety or buffer stock refers to excess inventory held to ensure uninterrupted production runs or deliveries to customers because of unpredictable, uncertain demand pattern of products. The underlying thinking is that some of the average stock should be devoted or reserved to address demand and delivery time variations in the short term.

- Speculative stock: This is inventory held for reasons other than meeting daily or current customer demand. The organisation can purchase large volumes of materials and obtain quantity discounts because of a possible strike action, possible material deficiencies, expected price increases, amongst others.

- Seasonal stock: It is a type of speculative stock and seeks specifically to maintain stable production runs and a stable working condition by accumulating year-round unavailable inventories (e.g. agricultural products, fashion products, school wears, and others) before its consumption season starts.

- Dead stock: This is a type of inventory whose demand is nonexistent, at least immediately. Management faces the dilemma either to keep the dead stock on hand or to get rid of the inventory. One reason that can motivate management to keep this type of inventory on hand is the expectation of the demand for such inventory at some point in the near future. In addition, regardless of the cost implication, management may still keep this stock for customer service purposes. 


\section{Inventory management}

Managing inventory is vital for organisations as it affects how they perform financially and how they adequately handle customer service levels. Alim and Beullens (2020:667) described inventory management as the control of amounts of inventories held in stock over a period of time. According to Kamau and Kagiri (2015:74), inventory management emphasises a continuous flow of inventory to ensure uninterrupted sales resulting in efficient customer service. Harmen and Yuniasih (2017:94) explained that inventory management comprises activities related to planning, implementing and monitoring of material requests so as to be able to timeously supply them and to optimally maintain levels of inventory. Milondzo and Mashau (2015:140) indicated that the management of inventory ensures that all the materials required in the organisation are visible, traceable and are known in terms of location, number and size throughout the supply chain, thus enabling the organisation to satisfy customer demand. Mangaan and Lalwani (2016:167) asserted that good inventory management maintains a constant flow of inventory to avoid interruptions in the supply chain. Raphella, Nathan and Chitra (2014:1) opined that an effective inventory management must:

- Guarantee an uninterrupted supply of raw materials to enable continuous production;

- Maintain ample finished goods inventory for smooth sales and proficient customer service;

- Reduce carrying costs and time; and

- Control investment in inventory by keeping it at best level and maintaining appropriate stocks of raw materials in periods of diminutive supply and foreseen price changes.

Mwangi and Nyambura (2015:65) stated that properly managed inventory plays a significant role in assisting organisations to reach their profit margins. Kamau and Kagiri (2015:73) assessed the relationships between inventory management practices and organisational competitiveness in Kenya and found that the use of inventory management methods had an impact on profit hikes, client satisfaction, market share growth and good return on investment. In his concluding statement, Kontuš (2014:245) indicated that successful inventory management is characterised and reflected by minimisation of inventory levels, lowering of costs and improvements in profitability.

\section{Inventory policy and implementation}

Inventory policies are said to serve various purposes, depending on the nature of inventory to be managed. For instance, one of the purposes of the inventory policy is to establish rules and processes that guarantee the accountability and safeguarding of all movable assets (American University 2017:1). The Transnet Inventory Policy (2010:3) states that the purpose of inventory policy is to explain Transnet's business approach to inventory management. The policy aims to outline the principles of inventory management. Eskom's inventory policy is contained in its Procurement and Supply
Chain Management Procedure. The purpose of the Procurement and Supply Chain Procedure is to outline the processes and procedures to be adhered to by commercial practitioners across the various operating units, when providing in customers' requests with clarity, efficiency and accountability (Eskom's Procurement and Supply Chain Management Procedure 2014:3).

Three types of costs are generally considered when setting and managing inventory policies and can be described as follows (Riza et al. 2018:212-213; Singha et al. 2017:2):

\section{Holding costs}

Holding costs are costs related to the physical storage of inventories and include the following (Horn et al. 2014:82):

- Capital or opportunity cost: Capital or opportunity cost is the capital tied up in inventory and unavailable for usage in the organisation's business operations or attractive business opportunities. Capital or opportunity cost is regarded as a loss for the organisation as the capital tied up in inventory could have benefited the organisation if invested in other lucrative business opportunities and generated profits quickly.

- Insurance costs: These are costs incurred for covering the organisation's inventories against fire damage, water or theft.

- Operational costs: These costs are incurred for maintaining the warehouse facility, storing materials and goods in own or leased storage facility, and handling of material equipment (i.e. storage racks, forklifts and shelves) in a warehouse and payment of warehouse personnel.

- Risk costs: Costs incurred for holding inventory and these emanate from stock obsolescence, stock damage or deterioration or stock pilferage.

\section{Ordering costs}

These are the costs associated with order fulfilment and include order preparation, delivery receipt and payment of invoices due (Paluch 2019:42), as well as the charges related to communication and handling of order-related documentations (Riza et al. 2018:212).

\section{Stockout costs}

Stockout costs, also called shortage costs or backorder costs, are the costs that occur when the suppliers fail to meet customers' demands for inventories (Alim \& Belleuns 2020:667). They may result in short-term or long-term lost sales (Riza et al. 2018:212), decrease of customer service levels, late deliveries, premium freight charges in an attempt to meet the agreed-upon delivery dates, in expediting, supplier visit costs, downtime, and overtime cost for additional production (Horn et al. 2014:84).

To be able to address the inventory management concern of 'when and how much to order', two conventional types of inventory policies are practically used. These include periodic review and continual review (Mangaan \& Lalwani 2016:174; 
Mpwanya 2016:558). In the periodic review, inventory managers issue replenishment orders at fixed intervals (e.g. fortnightly or weekly), whilst in continual review, inventory managers continuously monitor inventory levels and decide to replenish the inventory only when the reorder point is reached (Mangaan \& Lalwani 2016:174). In addition, Eynan and Kropp (2007) outline that whilst a periodically reviewed policy is believed to assist organisations to better coordinate replenishment decisions for assorted items, a continuous review policy exhibits improved performance for individualised items. Some of the drawbacks of using a periodic review policy include longer-term stockout security measures and greater stockout risks (Tagaras \& Vlachos 2001). Along these conventional inventory policies, $\mathrm{ABC}$ inventory classification and vendor-managed inventory are also used (Sanders 2012:250-261). The ABC inventory classification is based on the principle that items do not have an equal degree of importance in terms of their contribution to the total inventory value in the organisation. These items must therefore be managed by their class (A, B and C for highly valuable items, moderate value items and least value items, respectively). The ABC inventory classification is criticised for focusing on A-class items (a few critical) and not on C-class items (many trivial) (Mahagaonkar \& Kelkar 2017:616). A onecriterion approach for item classification and monitoring is quite limiting and inappropriate for nowadays complex business environment. With this regard, Balaji and Kumar (2014:465) argued that various criteria need to be considered when classifying and monitoring items in organisations. These criteria include critical nature of items, unit price, scarcity, annual demand rate, endurance, and the like.

In the above discussed inventory policies, customers are responsible for the management of purchased inventory. In vendor-managed inventory, the customer arranges with a vendor to handle its inventory located at its facility in terms of stocking, replenishment decision and display arrangements (Sanders 2012:265, 269), leaving the customer to focus on inventory demand accuracy (Afolabi, Onifade \& Olumide 2017:5).

The efficacy of inventory models or inventory policies can be generally influenced by the demand pattern of inventory to deliver to the customer. Consistent with this view, Taha (2007:430) stated that the demand pattern of products determines the complex nature of the inventory model or policy to be implemented in the organisation. Demand can mainly be deterministic or stochastic. A deterministic demand assumes that the demand for inventory to be sold to customers is known and infinitely constant or variable over a finite time. On the one hand, a demand is said to be stochastic when demand for inventory is uncertain and randomly distributed over time; stationary or non-stationary over time (Aloulou, Dolgui \& Kovalyov 2013:2294; Bushuev et al. 2015:284). Ma, Rossi and Archibald (2019:1492) stated that under most of real industry circumstances, demand for inventories is stochastic and non-stationary. Alim and Beullens (2020:668) argued that if supply lead time is more than the customer lead time, such type of demand has to be met using cycle stock and can therefore be categorised as stochastic.

The classic economic order quantity (EOQ) model, developed by Ford Harris in 1913, is considered as the simplest model as it has been designed to operate under a deterministic demand pattern, with a known and constant demand rate and lead time and no shortages or stockouts considered (Alim \& Belleuns 2020:668; Horn et al. 2014:88). However, this type of demand pattern occurs in rare occasions in practice, as compared to non-stationary, stochastic demand model that is considered as the most complex one and occurs more often in real business situations (Alim \& Belleuns 2020:668; San-José et al. 2017:619).

Extensions made to the classical EOQ model allow for inventory policy problems to be solved either in a deterministic setting or in a stochastic setting. For instance, Mishra et al. (2017) developed an EOQ model for deteriorating seasonal products that considers deterministic assumptions, where demand for inventory is a function of stock and selling price, and where shortages result in both full and partial backordering. The inventory policy aims to optimise ordering frequency, selling price and preservation of technology investment. The study proposes two EOQ models that can help control seasonal products, food products, amongst others. However, in a stochastic demand setting, the EOQ model uses the demand rate and the order quantity determined based on shortage costs or required service levels (Maddah \& Noueihed 2017). In their study, Maddah and Noueihed (2017:207) showed that the probabilised EOQ 'holds if the demand in the classic EOQ model is assumed to be generated from a renewal stochastic process'. The probabilised EOQ assumes that customer demand occurs randomly, one unit of the product at a time and time distribution between two demand periods is identical and independent. The model also displays complete insensitivity to demand variation and is worthwhile for practical applications (Maddah \& Noueihed 2017:207).

Sana (2015) presented an EOQ model for stochastically demanded inventories in a privately-owned, capacitylimited warehouse assuming that the lead time was zero and loss of demands during stockouts. Singha et al. (2017) extended Sana (2015)'s work by considering both periodically and continuously reviewed policies $(R, Q)$, backlogged and lost customer demands during stockout. They developed new mathematical equations to optimally determine order quantity and reorder point for inventory policies that address storage capacity constraints and minimise the total cost of inventory (ordering, holding, shortage, and over-ordering costs), where inventory demand and lead time are stochastically and discretely distributed.

Demands for certain products such as school wears and stationery or umbrellas, can be described as seasonal, because their demand is cyclical in nature and the total demand for such products is considered and assumed to be stationary. 
Silver, Pyke and Peterson (1998:67) indicated that both natural forces and human purchasing decisions are determinant for products of seasonal demand pattern. Whilst the demand for school wears and stationery is driven by school calendars, which are dictated by human decisions, the demand for umbrellas is driven by weather conditions (Hanke \& Wichern 2005:14).

A combination of demand patterns operating under deterministic or stochastic mode is modelled using mathematical algorithms (i.e. Alim \& Belleuns 2020; Chen et al. 2019; Mishra et al. 2017) or heuristic algorithms (i.e. Bragliaat et al. 2021; Ma et al. 2019; Sakulsom \& Tharmmaphornphilas 2019) or simulations to solve inventory policy-related problems. Some of the parameters considered in the inventory policy formulation include time, stock level and price. Under a deterministic demand with time-varying, stock-level dependent and price-dependent considerations, it can be assumed that the inventory replenishment rate follows an infinite horizon, but with a zero or negligible lead time, demand rate is a function of time, stock-level and price, inventory system allowing or disallowing shortages (stockout) and the backlog if shortages are allowed, item deterioration rate is exponentially distributed, inflation, use of single or multiple products, ordering cost considered based on lot size, holding cost per unit for inventory storage and backordering costs in case of stockouts, just to list few (Chen et al. 2019; San-José et al. 2017). It should be noted that these assumptions are inventory case-specific and may not all be considered in all inventory policy studies under a deterministic demand.

It is a well-established fact that stockouts often result in backordering and backlogging and its related costs in a deterministic setting. According to Singha et al. (2017:1), two types of demand behaviours are displayed during stockouts: lost sales in case of loss of demands; backlog, where demand fulfilment occurs when inventories are replenished and ready for delivery to customers. This behavioural pattern depends on the nature of products, market, and buyersupplier relationships. Both demand behaviours result in stockout or backorder costs that should be incurred. SanJosé et al. (2017:618) stated that full backorders occur when customers express the willingness to wait until the arrival of a new replenishment to the inventory system to meet all backorders. However, in most cases, demands for inventory are partially backlogged, whereby organisations are able to fulfil a percentage of orders and the unfulfilled demand will be met when a new stock is available (San-José et al. 2017:619).

The inventory policies developed in studies under deterministic demand, time varying, stock-level dependent and price-dependent mode focus on maximisation of the average profit per period, inventory cost minimisation or inventory optimisation. Some of the studies conducted under these circumstances include Bai et al. (2015); Srivastava and Singh (2017); Chen et al. (2019).
Other forms of inventory with time-dependent demand are products that deteriorate during their storage period. These products can be categorised into two types: (1) items such as vegetables, meat, fruit, flowers, blood, medicines, gasoline and radioactive that decay, damage or expire over time, and (2) items such as fashion and seasonal goods, mobile phones, and computer chips that lose their partial or total values because of new technological innovation (Panda, Khan \& Shaik 2019:147). Maragatham and Palani (2017:1840) argued that the optimal inventory policy needs to be determined for these deteriorating items taking into account the loss because of deterioration.

Other types of complex demand patterns have emerged in inventory management literature. These are: advance demand and deterministic and stochastic demand. In advance demand, some part of the demand is assumed to be known in advance, whilst some part is uncertain (Gallego \& Özer 2001:1344). Alim and Beullens (2020:668) described advance demand information as a demand 'placed in advance of their due dates'. Various studies have been conducted on advance demand information. For instance, in their investigation into inventory management under advance demand information, Gallego and Özer (2001) assumed that customers display different willingness to pay for additional amount to speed up their order fulfilment. They used dynamic programming to determine the reorder point and order up to level. They found that for the cases where ordering or setup cost is null, the demand information above lead time did not have any operational value. In an attempt to extend previous research on advance demand information, Wang and Toktay (2008) assumed that customers placing order for due dates can accept early order deliveries. They used some heuristic techniques to make inventory decisions and found that advance demand information to be an efficient instrument for decreasing inventory costs.

Deterministic and stochastic demand refers to inventory model or policy in which some of the part of the inventory demand operates under the deterministic condition, and some other part of demand displays the characteristics of a stochastically modelled inventory. Both demand characteristics can be exhibited simultaneously or in different phases when fulfilling customers' orders over time. Sobel and Zhang (2001) studied inventory management with a simultaneous deterministic and stochastic demand. They posited that if inventory demands under a stochastic and deterministic model occurs separately, demands for inventory with a deterministic component will not be backordered. They consider both demands concurrently to escape increased holding and ordering costs related to keeping inventory for both demands independently. Their study considers periodically reviewed policies with demand parity, in which the demand for the deterministic inventory component is posited to occur with zero shortages whilst the demand for stochastic inventory component can be subjected to backlog. Recently published studies in this development modelled inventory demand patterns based on stock, time, 
price, and deterioration parameters: Bai et al. (2015) and Chen et al. (2019).

Nyabwanga and Ojera (2012:15) indicated that inventory policies play a huge role in ensuring effective performance of inventory management in organisations. Bala (2014:951) advised that the effective management of inventories necessitates that a proper process supporting inventory policies be in place. In support of the above statement, this study argues that a proper process of inventory policies should be implemented to ensure that inventory policies achieve their intended goals. Garcia-Herreros et al. (2016:256) pointed out that inventory policies are determined by the traditional models of inventory management and are easy to implement. To have maximum or greater inventory policy effect on organisational performance, managers, inventory planners and end-users alike need to understand how to apply and implement the information contained in the inventory policy of their organisation. In addition, managers should be able to quantify the benefits that derive from inventory policy implementation. Emphasising the importance of employing skilled inventory staff, Mc Laughlin (1987:172) argued that the effectiveness of inventory policies largely depends on the skills and attitudes of the people involved in the implementation of the inventory policy. Organisations can establish exceptional inventory policies, but if these are not implemented, inventory policy objectives will not be met. Hanson et al. (2015:92) pointed out that the control of inventory is a managerial procedure for implementing inventory policies. It is therefore important that managers ensure the implementation of inventory policies in order for their departments to achieve their inventory management objectives.

The implementation of inventory policies serves as a catalyst for effective inventory control, reduction of inventory challenges and increased profit margins. Godana and Ngugi (2014:341), however, questioned the efficiency of inventory management procedures that are put in place in addressing discrepancies emanating from inventory levels. In response to the above concern, Nyabwanga and Ojera (2012:15) argued that inventory policies play a big role in augmenting inventory management performance. Central to the meaning and success of inventory policies is proper inventory policy implementation, because it is pointless to have inventory policies in place and not implementing them properly.

Mo et al. (2014:1297) emphasised that establishing good inventory policies and the effective implementation of these would result in the reduction of inventory carrying costs as the purchase for materials will be triggered by the customers' demands. Full implementation of inventory policy will lead to effective and efficient inventory management. As indicated by Mc Laughlin (1987:172), the effectiveness of any inventory policy depends on the skills and attitudes of the people who are meant to implement it. This means that organisations can have excellent inventory policies, but if the inventory policies are not fully and properly implemented, organisations will not be able to meet their inventory management objectives.

\section{Research methodology Research design}

In this study, a qualitative research design was adopted. A qualitative research design focuses on individuals' subjective lived experiences and the meanings attributed to those experiences (Dawson 2002:14; Starman 2013:30). This study explored the perceptions and subjective understanding of inventory staff (non-managerial and managerial staff) on the implementation of inventory policy in their respective organisations. As stated by Lambert and Lambert (2012:255) and Starman (2013:30), a qualitative research design aims to detail the participants' opinions and lived experiences about a phenomenon under investigation.

\section{Target population and sample}

The target population refers to the population of interest that a researcher decides to research on to achieve set objectives (Sekaran \& Bougie 2016:240). The target population for this research study consisted of materials requirement planners / inventory planners (non-managerial staff) and junior and middle materials managers at SOE 1 and SOE 2 (labels 'SOE 1 and SOE 2' used for anonymity and confidentiality purposes). This population selection is motivated by the fact that they directly deal with inventory management and are responsible for inventory policy implementation at SOE 1 and SOE 2.

The sample frame comprised a list of inventory staff working in the inventory management division in both managerial positions (junior and middle managers) and non-managerial positions (inventory planners). The inventory staffs were selected using a non-probability purposive sampling at SOE 1 and SOE 2 located in the Gauteng Province. The sample elements of non-probability sampling are selected based on the researcher's judgement (Patton 2015; Sharma 2017:750). Yin (2011:88) described purposive sampling as a sampling method where the selection of participants is informed by the aims and properties or characteristic attributes of the study. The selection criteria for participants (inventory staff) were knowledge of inventory management and policies, direct involvement in the management of inventory and implementation of the inventory policies. Senior inventory managers were excluded in the sample frame of this study because they did not meet the last two selection criteria.

Unlike quantitative research that uses a pre-determined sample size to guide data collection, this qualitative study had no pre-determined sample for participants. Instead, it used a sequential approach in data collection, where the sample size is determined by the saturation point.

\section{Data collection}

Secondary data were collected and consisted of inventory policies, process control manuals, work instructions and financial statements of SOE 1 and SOE 2. This aided in 
developing an overall understanding regarding the implementation of inventory policies at SOE 1 and SOE 2.

Primary data were also collected by means of face-to-face semi-structured interviews with 24 participants, of which 15 worked for SOE 1 and nine worked for SOE 2. These semistructured interviews were held from March 2018 to July 2018 around the Gauteng Province at a date, time and place arranged with the participants. The average interview duration time was between $30 \mathrm{~min}$ and $45 \mathrm{~min}$ and permission was sought to voice record the interviews prior to commencement of the interview.

\section{Data analysis}

The interview transcripts were analysed manually and thematically. Thematic analysis is a generally recommended approach for qualitative data analysis and it consists of identifying themes and reporting of patterns that emerge from data immersion (Wagner, Kawulich \& Garner 2012:231). The thematic analysis of interview transcripts performed in this article followed the four steps suggested by Kumar (2011:278). These steps included identification of the main themes, assignment of codes to the main themes, classifying participants' responses under the main themes, and integrating themes and responses into the research report. The field notes made during the interviews assisted in providing context to the participants' opinions and lived experiences in the transcripts and served as supporting data for confirming the participants' opinions and lived experiences on the extent of adherence to inventory policies at SOE 1 and SOE 2.

\section{Trustworthiness}

Trustworthiness refers to different measures taken during data analysis, reporting, discussion of findings and conclusion making to create confidence in the research process (Maree 2013:113). Four measures were applied to establish trustworthiness in this study: credibility, transferability, dependability and conformability (Merriam 2015:234; Shenton 2004:64). Credibility was established through regular debriefing sessions with researcher supervisors and scrutiny of findings of past studies. Sufficient information about the exploration of research sites was given to allow for transfer of the findings of the current study to other environments and also to provide an accurate description of the main assumptions of this study. This, therefore, ensured transferability of findings. To ascertain dependability, research methods used were meticulously described to allow for future researchers to repeat this study and possibly achieve similar outcomes. Finally, an audit trail was performed to track and trace the progress with clear description of techniques adopted and to evaluate the resolutions taken and their implementation through the different phases of the study. This established conformability of the findings.

\section{Ethical considerations}

This study observed ethical requirements and obtained ethical clearance from a South African institution of higher learning. The permission from SOE 1 and SOE 2 was obtained to conduct interviews with their staff prior to commencement of data collection. An informed consent form was provided to all participants to peruse and understand the purpose and benefits of the study, the task at hand (what participants are required to do) and the participants' rights during and after the interview sessions. These rights include voluntary participation and withdrawal from the study at any given time, amongst others. Participants were also assured of confidentiality and anonymity when reporting and discussing the research findings in the study.

\section{Findings of the study Themes that have emerged from the analysis of interview transcripts}

Four themes emerged from the analysis of interview transcripts of participants, namely, adherence to inventory policy, inventory policy violations, implementation extent of inventory policy, inventory growth rate and the associated increase in inventory carrying costs and lack of inventory planners' planning skills. The themes are discussed in light of the existing literature to understand to what degree inventory policies are implemented at each SOE. To ensure anonymity and confidentiality of the inventory personnel who willingly participated in this study and the SOEs they work for, pseudonyms were used and therefore labelled as SOE 1 and SOE 2.

\section{Adherence to inventory policy}

Adhering to established inventory policies enables organisations to avoid financial losses that results from inventory policy flouting. Effective implementation of inventory policy ensures inventory availability and enables organisations to be able to provide excellent services to internal and external customers. The majority of participants have mentioned that there has been, to some extent, adherence to or compliance with inventory policies by inventory staff of each SOE. This fact is reflected in the quotes below for SOE1:

'I can't afford not to run the ABC and ensure that the items that I plan for are correctly classified to eliminate any violations. I may be penalised if my stock holding increases due to the fact that I did not pay enough attention on my A-items as the policy stipulates.' (Participant 12, 49 years, female, SOE 1)

'Adherence to the inventory policy is the life-blood of planning. I don't think that my items are in violation as I keep a check on my stock value and there has not been any major increase in stock value on the items that I plan for, the policy is well applied when it comes to planning of the items are am responsible for.' (Participant 9, 47 years, male, SOE 1)

A similar view was shared by the participants of SOE 2, as reflected in the quotes below:

'I always ensure that I apply the policy by ensuring that my A-items are $65 \%$, B-items are $25 \%$, C-items are $7 \%$ \& D-items are $3 \%$; I always apply the inventory policy well on my inventory items.' (Participant 2, 45 years, male, SOE 2) 
'I run the ABC religiously; I think my items are not in violation of the policy as I always apply and adhere to the inventory policy guidelines.' (Participant 5, 45 years, male, SOE 2)

The examination of the inventory policies of both SOEs reveals different classification for inventory mix. Although both SOEs use the ABC principle in the classification of their items, SOE 2 classifies its items up to D, whilst SOE 1's items classification ends with $\mathrm{C}$. In terms of percentage allotted to each segmented class, SOE 2 used percentage allotments of $65 \%, 25 \%, 7 \%$ and $3 \%$ for A, B, C and D-class items, respectively. For SOE 1, the percentage allotment of items include $80 \%$ for A-class items, $15 \%$ for B-class items and 5\% for C-class items. The inventory staff who adhere to or comply with the inventory policies of their organisations need to be incentivised in order to stimulate good inventory management practices. Consistent with this view, Tyler (2005:1287) claimed that ensuring that the employees adhere to the organisational rules and policies is an important factor to effective management of inventory and functioning of the entire organisation.

\section{Inventory policy violations}

Inventory policy violations occur when inventory staff deliberately decide to deviate from the rules, guidelines and principles that govern inventory policies. Whilst some inventory staff chose to faithfully practise the ABC principle, as stipulated by the inventory policies of their organisations, other inventory staff disregarded the application of the ABC principle when handling inventory in their organisations. This violation of inventory policy frustrated those inventory planners who faithfully applied the ABC principle, as stated by one of the participants who work for SOE 1 :

'There are few of us, inventory planners, who plan correctly by ensuring that we abide by the $\mathrm{ABC}$ rules in the policy which indicate that allocation must be made into each class of items according to $80 \%=\mathrm{A}, 15 \%=\mathrm{B}$ and $5 \%=\mathrm{C}$, but in most cases the efforts of planners who plan according to the policy and work instructions are over shadowed by the ones who are in violation of the policy.' (Participant 15, 34 years, male, SOE 1)

Some participants who work for SOE 2 chose to use other preferred methods instead of the $A B C$ classification as required by the inventory policies of their $\mathrm{SOE}$, whilst other participants have indicated not being exposed to systems applications and products (SAP) in data processing to be able to classify items according to the ABC system:

'I have been doing this job for a while now and I don't have to rely on ABC classification.' (Participant 3, 63 years, male, SOE 2)

'I don't have access to run ABC to enable classification to be possible.' (Participant 4, 38 years, male, SOE 2)

It is a fact that some inventory planners notice violations of inventory policy in their organisations and do not question the violation in team meetings. This striking point is indicated in the quote below:

'The biggest violation I see is that we don't question end users, we just buy the quantities stipulated for fear of being wrong then eventually being exposed.' (Participant 14, 36 years, female, SOE 1)

It is clear from the above statements that each SOE needs to train its inventory staff on the importance of complying with inventory policies to enable better inventory management performance and should also take the necessary disciplinary action against those who violate inventory policies. This action would serve as an accountability measure for any inventory policy violation and thereby ensure full compliance or adherence to inventory policies in each SOE towards their path of profitability and sustainability. In addition, violation of inventory policy could result in either over or under stocking, which in turn leads to wasteful expenditure. To prevent this, Lysons and Farrington (2006:319) advised inventory managers that 'stock should be well managed in order to circumvent irregular expenditure on the various classes of inventory'.

\section{Implementation extent of inventory policy}

Hanson et al. (2015:92) stated that organisations should give relevant instructions to warehouse and procurement managers that must be adhered to in order to avoid inventory and financial losses. These instructions are encapsulated in the inventory policies and aim to minimise or eliminate inventory losses, if they are well understood and properly implemented by inventory staff.

Participants who work for SOE 1 have indicated that inventory policies of their organisations are not fully implemented. End users have been identified as the biggest violators of inventory policies, because of lack of training on the importance of adhering to inventory policies and its consequences. This is highlighted in the following quotations:

'The policy is not fully implemented but there are pockets of excellence. I have noticed that end users who are the biggest transgressors of the policy have not been educated on the policy and how it affects the end users in their daily lives at work.' (Participant 1, 31 years, female, SOE 1)

'No, the existing policy is not implemented fully; [and] the proof is in the monthly dashboard results.' (Participant 10, 44 years, female, SOE 1)

Partial implementation of inventory policy has also been mentioned by one of the participants of SOE 2 , as evidenced in the quote below:

'If I were to say "no," it would mean that I come to work and do nothing at the same time. I cannot say "yes" as it would mean that I am declaring that everything on that policy is being done accordingly. It is safe for me to say, it is somewhat implemented.' (Participant 9, 29 years, male, SOE 2)

Despite the experience and exposure to inventory management, SOE 1 and SOE 2 failed to ensure full implementation of inventory policy. As indicated by Mohubedu (2017:19), failure to implement inventory processes, including inventory policy, would result in organisational failures. Based on this warning and the 
participants' perspectives as mentioned above, it is paramount for inventory managers of SOE 1 and SOE 2 to organise regular training on the topic of inventory policy, inventory management performance and the benefits associated with compliance with inventory policies. In addition, consequence management for violators of inventory policies need to be implemented to instil accountability in the mind-set of end users and inventory staff in both managerial and non-managerial positions in SOE 1 and SOE 2. These measures are altogether important avenues towards full implementation of inventory policy, containment of inventory costs, optimisation of inventory performance objectives and enhanced profitability at each SOE.

\section{Inventory growth rate and increased inventory carrying costs}

In this article, inventory growth rate is described as the degree to which stock increases during a given period in an organisation. One of the participants who work for SOE 1 has indicated that his organisation's purchasing divisions buy stocks at differing prices, which leads to an increase in inventory rate and in inventory value:

' $[\ldots T]$ he inventory rate according to me has been growing due to differing price on items ... Various divisions can buy stock at different prices from the same supplier, this increases inventory value drastically.' (Participant 13, 57 years old, male, SOE 1)

A participant who works for SOE 2 mentioned that some inventory planners purchase stock in violation of the organisation's inventory policy. This led to inventory growth rate, as illustrated by the quotes below:

'There are some planners who do not apply their minds when making purchases, they buy just in case it is required in future. There are some who work outside the policies and procedures of inventory management, and the minute one deviates from the process, we are bound to have such challenges as inventory growth rate.' (Participant 1, 39 years, female, SOE 2)

Another more experienced participant working for the same organisation not only acknowledged an increase in inventory number and in value, but also indicated that no analysis has been done to determine the factors contributing to such an increase:

'According to my knowledge or recollection over the years, there has been no analysis done to verify what is contributing to the inventory increase ... What I know for sure is that inventory is increasing both in number and value.' (Participant 3, 63 years old, male, SOE2)

It is clear from the above facts that inventory growth rate is an outcome of violation of inventory policy by inventory planners and inventory managers who work for SOE 1 and SOE 2. This is because the inventory policy of each SOE stipulates when and how much to order or purchase as triggered by customer demand for each SOE. The failure of SOE 1's and SOE 2's inventory planners and inventory managers to inform their stock purchasing decision on their inventory policy resulted in excess stock and in increase in inventory carrying costs for SOE 1 and SOE 2. This is consistent with the observation by Horn et al. (2014:81) that states that 'the more stock carried, the higher the carrying costs'. Inventory costs related to excess stock holding can be minimised if SOE 1 and SOE 2 enforce compliance with their inventory policies. Excess stock means that each SOE cannot quickly convert the cash tied up in the inventory for other operational needs. This challenge constrains SOE 1 and SOE 2 thus incurring unnecessarily inventory carrying costs like insurance costs, amongst others. This also increases the operating costs of SOE 1 and SOE 2 whilst negatively affecting the profit-making capabilities of each SOE in terms of liquidity and cash flow.

\section{Lack of inventory planners' planning skills}

The education level of inventory staff and the lack of inventory planning skills were cited by some of the participants as impediments to inventory policy implementation at each SOE. The views of SOE 1's participants clearly indicated that their organisation needs to focus more on upskilling inventory planners to help them understand the importance and benefits of fully implementing inventory policies. Such upskilling of inventory management, particularly inventory planning, needs to be facilitated by tertiary institutions, as the following excerpts from SOE 1's participants suggest:

'No, the policy is not implemented due to the lack of planning expertise of the inventory staff. Most of us are reluctant to further our studies due to the fact that we are required to pay back the study amount in the event that we fail. Internal courses do not help that much because the same people who facilitate these courses are the same people who allow end users to bypass the inventory policies.' (Participant 2, 34 years, male, SOE 1)

'I can't help but raise my concerns around the level of skill that is present in our inventory environment. It is a known fact that, the materials management section has always been used as a dumpsite for employees who could not perform certain duties in their departments. Bear in mind that these people look after the organisation's biggest asset. I feel that a skills audit has to be conducted, thereafter come up with the best strategy to upskill our planners. Currently, there is more fire-fighting and less planning.' (Participant 7, 39 years, male, SOE 1)

The need for inventory planning training was also cited by one of the participants who work for SOE 2. This participant suggests that training needs to be organised from the top-level managers to the employees in non-managerial level:

'Great emphasis is not put on educating all the role players in the supply chain, from the top managers to employees on the shop floor. We do not have adequate inventory planners who are qualified at what they do, which questions the expertise that our current inventory planners have in inventory planning.' (Participant 7, 30 years, female, SOE 2)

In light of the issue raised by the participants about the importance of skills of inventory staff, Naliaka and Namusonge (2015:95) highlight the fact that the skills for inventory management are precious as they assist in providing supply policies for the organisation's future needs 
and in establishing supply management policies to support organisational strategies. Milondzo and Mashau (2015:141) argue that because holding inventory is a risky business, it is imperative for inventory practitioners in organisations to possess the required skills and knowledge when managing inventory. Singh and Twalo (2014:82) assert that a lack of skills impedes effective customer service and may lead to malpractice in most cases. Each SOE needs to invest in the upskilling of their inventory staff if they are to succeed in inventory management, as indicated by participants and also as advised by the various authors cited in the text above. This would empower inventory planners and other staff involved in different aspects of inventory management on the role, importance and benefits of fully implementing their inventory policies and make them become more pro-active in the handling of bottlenecks.

\section{Linking findings to the specific objectives}

It is clear from the discussed findings that some inventory planners and inventory managers of SOE 1 and SOE 2 adhere to their inventory policies, whilst others violate these policies. Each SOE needs to incentivise those who adhere to the inventory policy and implement consequence management for those who violate inventory policy to ensure better inventory management performance at each SOE. This is consistent with Tyler (2005:1287) and Lysons and Farrington (2006:319) who advocate adherence to inventory policies as a mechanism for improving inventory management performance.

The first specific objective for this study was to assess the extent to which the established inventory policy of each of the selected SOE is implemented. It was found that the inventory policy of each SOE was not fully implemented. Therefore, there is a need for each SOE to organise training on inventory policy, inventory planning, and the benefits associated with full implementation of inventory policy. Also, each SOE needs to implement consequence management for violators of inventory policies as indicated above. Both measures are important to ensure accountability, containment of inventory costs, optimisation of inventory performance objectives and enhanced profitability at each SOE.

The second specific objective was to evaluate the impact of non-adherence to the inventory policy on inventory costs of each of the selected SOEs. The finding suggests that violation of inventory policy at each SOE results in excess inventory carrying and the associated inventory carrying costs. This increases operating costs of each SOE and negatively affect the liquidity and cash flow of each SOE.

\section{Limitations and future research}

As with other studies, the findings of the current study have some limitations. Firstly, the sample was limited to the employees at SOE 1 and SOE 2 located in the Gauteng Province of South Africa. Secondly, only 24 inventory staff members willingly agreed to participate in this study out of 60 inventory staff working for SOE 1 and SOE 2 in the
Gauteng Province. Thirdly, the generalisation of this study's findings was difficult because of the use of the qualitative approach and purposive sampling.

Future researchers could study the inventory policy implementation in privately owned organisations and government departments such as the Department of Health, Human Settlement, Public Works and others in South Africa. A similar study could be conducted using mixed method designs or the quantitative method and extended to all nine provinces of South Africa.

\section{Recommendations}

Based on the findings of this study, a number of recommendations are made. Firstly, SOE 1 and SOE 2 should implement consequence management for violators of inventory policies and stimulate full adherence to inventory policy guidelines. Secondly, as part of good governance and compliance, internal audits must also be done from time to time to evaluate whether inventory staff are implementing the inventory policy guidelines as prescribed. Deviations must be recorded and used for training and education purposes. Thirdly, a compliance and enhancement tool must be added into SAP with monitoring functionality to prompt an inventory planner to take corrective action every time a deviation is detected.

\section{Conclusion}

The proper management of inventory is fundamental for the survival of many organisations because of the money that is tied up in the inventory. This qualitative study was undertaken to explore the perspectives of inventory staff regarding the implementation of inventory policies to enhance inventory management performance of SOE 1 and SOE 2 in the Gauteng Province of South Africa. These perspectives were obtained through semi-structured interviews with 24 inventory staff in various locations around the Gauteng Province. This study found that inventory policies were, to some extent, adhered to by the majority of the inventory staff of SOE 1 and SOE 2. Adhering to inventory policy appears to be an important driver for each SOE to be able to effectively meet their inventory management objectives and ensure improved inventory management performance, which in turn contribute to the overall organisational performance. Despite adherence to inventory policy, it was also found that some inventory staff violated the inventory policy in their daily inventory management practices. This negatively affects the inventory management performance of SOE 1 and SOE 2 and therefore, consequence management should be implemented to instil the culture of inventory policy adherence and minimise inventory costs. This study revealed that inventory policies were partially implemented, despite the fact that most of inventory staff were experienced. These findings seemed to balance the two divergent views of inventory staff who participated in this qualitative study. However, full implementation of inventory policy is needed for SOE 1 and SOE 2 to be able to contain 
their inventory costs, optimise their inventory performance objectives and become profitable. Finally, the study found that inventory planners lacked inventory planning skills and it is therefore paramount for SOE 1 and SOE 2 to commit financially to upskilling of their inventory planners and other inventory staff on the topic of inventory management in general and implementation of inventory policy in particular. Such training would assist in preventing the violation of inventory policy and inventory bottlenecks.

\section{Acknowledgements}

The authors would like to thank the various research participants for their sacrifices, commitments and inputs to this study.

\section{Competing interests}

The authors have declared that no competing interests exist.

\section{Authors' contributions}

The article was drafted from the M Tech dissertation of A., whose dissertation was supervised by M.F. and K.R. All authors contributed equally to this work.

\section{Ethical considerations}

The Faculty of Management Sciences Research Ethics Committee reviewed the documents at its meeting on 08 September 2017. The study is approved. Faculty Committee for Research Ethics, Ref \#: FCRE2017/FR/09/013-MS (2).

\section{Funding information}

This research received no specific grant from any funding agency in the public, commercial or not-for-profit sectors.

\section{Data availability}

Data sharing is not applicable to this article as no new data were created or analysed in this study.

\section{Disclaimer}

The views and opinions expressed in this article are those of the authors and do not necessarily reflect the official policy or position of any affiliated agency of the authors.

\section{References}

Abdel-Aal, M., El-Sharief, M.A., El-Deen, A.E. \& Nassr, A., 2010, 'A framework for evaluating and comparing inventory control policies in supply chains', Journal of Engineering Sciences 38(2), 449-465. https://doi.org/10.21608/jesaun.2010. 124377

Afolabi, O.J., Onifade, M.K. \& \& Olumide, O.F., 2017, 'Evaluation of the role of inventory management in logistics chain of an organisation', Scientific Journal on Transport and Logistics 8(2), 1-11. https://doi.org/10.1515/logi-2017-0011

Alim, M. \& Beullens, P., 2020, 'Batch ordering inventory management under the mixed demand information: A case study', Konya Journal of Engineering Sciences 8(3), 666-677. https://doi.org/10.36306/konjes.599332

Aloulou, M., Dolgui, A. \& Kovalyov, M., 2013, 'A bibliography of non-deterministic lotsizing models', International Journal of Production Research 52(8), 2293-2310. https://doi.org/10.1080/00207543.2013.855336
Bai, Q.-G., Xu, X.-H., Chen, M.-Y. \& Luo, Q., 2015, 'A two-echelon supply chain coordination for deteriorating item with a multi-variable continuous demand
function', International Journal of Systems Science: Operations \& Logistics 2(1), function', International Journal of Systems Science: Operat
49-62. https://doi.org/10.1080/23302674.2014.998314

Balaji, K. \& Kumar, V.S.S., 2014, 'Multi-criteria inventory ABC classification an automobile rubber components manufacturing industry', Procedia CIRP 17, 463-468. https://doi.org/10.1016/j.procir.2014.02.044

Bala, K., 2014, 'Supply chain management, some issues and challenges: A review', International Journal of Current Engineering and Technology 4(2), 946-953.

Bowersox, D.J., Closs, D.J. \& Cooper, M.B., 2010, Supply chain logistics management, 3rd edn., McGraw, New York.

Bragliaa, M., Castellanob, D., Santillob, L. \& Song, D., 2021, 'Controlling lead times and minor ordering costs in the joint replenishment problem with stochastic demands under the class of cyclic policies', International Transactions in Operational Research 28, 376-400. https://doi.org/10.1111/itor.12571

Bushuev, M., Guiffrida, A., Jaber, M. \& Khan, M., 2015, 'A review of inventory lot sizing review papers', Management Research Review 38(3), 283-298. https://doi. org/10.1108/MRR-09-2013-0204

Chen, L., Chen, X., Keblis, M.F. \& Li, G., 2019, 'Optimal pricing and replenishment policy for deteriorating inventory under stock-level-dependent, time-varying and price-dependent demand', Computers \& Industrial Engineering 135, 1294-1299. https://doi.org/10.1016/j.cie.2018.06.005

Dawson, C., 2002, A practical research methods: A user friendly guide to mastering research, 1st edn., Cromwell Press, Oxford.

Eskom Holdings Soc. Ltd., 2014, Procurement and supply chain policy, Internal Document. viewed 28 May 2018, from http://www.eskom.co.za.

Eynan, A. \& Kropp, D.H., 2007, 'Effective and simple EOQ-like solutions for stochastic demand periodic review systems', European Journal of Operations Research 180(3), 1135-1143. https://doi.org/10.1016/j.ejor.2006.05.015

Fogarty, D.W., Blackstone, J.H. \& Hoffmann, T.R., 1991, Production \& inventory management, 2 nd edn., South-Western, Cincinnati, $\mathrm{OH}$.

Gallego, G. \& Ozer, O., 2001, 'Integrating replenishment decisions with advance demand information', Management Science 47(10), 1344-1360. https://doi. org/10.1287/mnsc.47.10.1344.10261

Garcia-Herreros, P., Agarwal, A., Wassick, J. M. \& Grossmann, I. E., 2016, 'Optimizing inventory policies in process networks under uncertainty', Computers \& Chemical inventory policies in proces
Engineering $92,256-272$.

Godana, B.E. \& Ngugi, K., 2014, 'Determinants of effective inventory management at Kenol Kobil Limited', European Journal of Business Management 1(11), 341-361.

Hanke, J.E. \& Wichern, D.W., 2005, Business forecasting, Prentice Hall, Hoboken, NJ.

Hanson, O.Y., Ackah, D. \& Agboyi, M., 2015, 'Assessing the impact of efficient inventory management in an organisation', International Journal of Advanced Research in Computer Science and Software Engineering 5(8), 86-103.

Harmen, F.A. \& Yuniasih, R., 2017, 'Inventory management analysis and improvement of inventory control procedures: Case study in the secretariat of the tax court', in proceedings of the 6th International accounting conference, Yogyakarta, proceedings of the 6th Internation
Indonesia, August 93-98, Atlantis Press.

Horn, G., Badenhorst-Weiss, H., Cook, G., Heckroodt, S., Howell, J., Phume, T.B. et al., 2015, Supply chain management: A South African approach, 2nd edn., Oxford University Press, Cape Town.

Jacobs, F.R. \& Chase, R.B., 2014, Operations and supply chain management, 14th edn. Mc Graw-Hill, New York, NY.

Jalali, H. \& Nieuwenhuyse, I.V., 2015, 'Simulation optimization in inventory replenishment: A classification', IIE Transactions 47(11), 1217-1235. https://doi. org/10.1080/0740817X.2015.1019162

Kamau, W.L. \& Kagiri, A.W., 2015, 'Influence of inventory management practices on organizational competitiveness: A case of Safaricom Kenya Ltd.', International Academic Journal of Procurement and Supply Chain Management 1(5), 72-98.

Kontuš, E., 2014, 'Management of inventory in a company', Original Scientific Article 2, 245-256.

Kumar, R., 2011, Research methodology, 4th edn., Sage, Thousand Oaks, CA

Lambert, V.A. \& Lambert, C.E., 2012, 'Qualitative descriptive research: An acceptable design', Pacific Rim International Journal of Nursing Research 16(4), 255-256.

Lysons, K. \& Farrington, B., 2006, Purchasing and supply chain management, 7th edn., Prentice Hall, Essex.

Maddah, B. \& Noueihed, N., 2017, 'EOQ holds under stochastic demand, a technical note', Applied Mathematical Modelling 45, 205-208. https://doi.org/10.1016/j. apm.2016.12.026

Mahagaonkar, S.S. \& Kelkar, A.A., 2017, 'Application of ABC analysis for material management of a residential building', International Research Journal of Engineering and Technology 4(8), 614-620.

Mangaan, J. \& Lalwani, C., 2016, Global logistics and supply chain management, 3rd edn., Wiley, Chichester.

Maragatham, M. \& Palani, R., 2017, 'An inventory model for deteriorating items with lead time, price dependent demand and shortages', Advances in Computational Sciences and Technology 10(6), 1839-1847.

Maree, K., 2013, First steps in research, 13th edn., Van Schaik Publishers, Pretoria.

Ma, X., Rossi, R. \& Archibald, T., 2019, 'Stochastic inventory control: A literature review', IFAC PapersOnLine 52(13), 1490-1494. https://doi.org/10.1016/j. ifacol.2019.11.410

Mc Laughlin, M.W., 1987, 'Learning from experience: Lessons from policy implementation', Educational Evaluation and Policy Analysis 9(2), 171-178. https://doi.org/10.3102/01623737009002171 
Mensah, O.E., 2015, 'The effect of inventory management practices on service delivery at St. Martin's hospital', MBA dissertation, Amansie-West Knust School of Business, Kumasi.

Merriam, S., 2015, Qualitative research: A guide to design and implementation: Revised and expanded from qualitative research and case study applications in education, 2nd edn., Josse-Bass Wiley, San Francisco, CA.

Milondzo, K.S. \& Mashau, M.A., 2015, 'Exploring the consequences of inadequate inventory management accountability within Eskom, Limpopo', Journal of Business Administration and Management Sciences Research 4(7), 140-151.

Mishra, U., Cárdenas-Barrón, L.E., Tiwari, S., Shaikh, A.A. \& Treviño-Garza, G., 2017, ‘An inventory model under price and stock dependent demand for controllable deterioration rate with shortages and preservation technology investment', Annals of Operations Research 254, 165-190. https://doi.org/10.1007/s10479-017-2419-1

Mo, D.Y., Tseng, M.M. \& Cheung, R.K., 2014, 'Design of inventory pools in spare part support operation systems', International Journal of Systems Science 45(6) 1296-1305. https://doi.org/10.1080/00207721.2012.761466

Mohubedu, N.C., 2017, 'Inventory management in the electricity industry in South Africa: A case study', MCom dissertation, University of KwaZulu Natal, Durban.

Mpwanya, M.F., 2016, 'The relationship between inventory-management policies and customer service in manufacturing industries logistics in Gauteng province, South Customer service in manufacturing industries logistics in Gauteng provic
Africa', WSEAS Transactions on Business and Economics 13, 556-572.

Mwangi, W. \& Nyambura, M.T., 2015, 'The role of inventory management on performance of food processing companies: A case study of Crown Food Limited Kenya', European Journal of Business \& Social Sciences 4(4), 64-78.

Naliaka, V.W. \& Namusonge, G.S., 2015, 'Role of inventory management on competitive advantage amongst manufacturing firms in Kenya: A case study of Unga Group Limited', International Journal of Academic Research in Business and Social Sciences 5(5), 87-104. https://doi.org/10.6007/IJARBSS/v5-i5/1595

Nyabwanga, R.N. \& Ojera, P., 2012, 'Inventory management practices and business performance for small-scale enterprises in Kenya', KJBM 4(1), 11-28.

Paluch, W., 2019, 'The use of the EOQ model in inventory management in the supply chain on the example of Bahlsen Polska', Logistics and Transport 3(43), 41-46.

Panda, G.C., Khan, M.A.-A. \& Shaikh, A.A., 2019, 'A credit policy approach in a twowarehouse inventory model for deteriorating items with price- and stockdependent demand under partial backlogging', Journal of Industrial Engineering International 15, 147-170. https://doi.org/10.1007/s40092-018-0269-3

Panday, R. \& Navanti, D., 2021, 'Inventory management evaluation and inventory forecast using EOQ', Syntax Literate: Jurnal Ilmiah Indonesia 6(1), 395-406. https://doi.org/10.36418/syntax-literate.v6i1.2286

Patton, M.Q., 2015, Qualitative research and evaluation methods, 3rd edn., Sage, Thousand Oaks, CA.

Penny, A., 2019, 'The influence of inventory policy on inventory management performance in selected state-owned enterprises in Gauteng', M Tech dissertation, Tshwane University of Technology, Tshwane.

Raphella, A.S., Nathan, G.S. \& Chitra, G., 2014, 'Inventory management: A case study', International Journal of Emerging Research in Management and Technology 3(3), 1-9.

Riza, M., Purba, H.H. \& Mukhlisin, 2018, 'The implementation of economic order quantity for reducing inventory cost', Research in Logistics and Production 8(3), 207-216.

Sakulsom, N. \& Tharmmaphornphilas, W., 2019, 'Heuristics for a periodic-review policy in a two-echelon inventory problem with seasonal demand', Computers \& Industrial Engineering 133, 292-302. https://doi.org/10.1016/j.cie.2019.05.017

Sana, S.S., 2015, 'An EOQ model for stochastic demand for limited capacity of own warehouse', Annals of Operations Research 233, 383-399. https://doi. org/10.1007/s10479-013-1510-5
Sanders, N.R., 2012, Supply chain management: A global perspective, 1st edn., John Wiley \& Sons Inc., Denver, CO.

San-José, L.A., Sicilia, J., González-De-la-Rosac, M.G. \& Febles-Acostac, J., 2017, Optimal inventory policy under power demand pattern and partial backlogging', Applied Mathematical Modelling 46, 618-630. https://doi.org/10.1016/j. apm.2017.01.082

Sekaran, U. \& Bougie, R., 2016, Research methods for business, 7th edn., Wiley, West Sussex.

Sharma, G., 2017, 'Pros and cons of different sampling techniques', International Journal of Applied Research 3(7), 749-752.

Shenton, A.K., 2004, 'Strategies for ensuring trustworthiness in qualitative research projects', Education for Information 22(2), 63-75. https://doi.org/10.3233/EFI2004-22201

Silver, E.A., Pyke, D. \& Peterson, R.F., 1998, Inventory management and production planning and scheduling, John Wiley and Sons, New York, NY.

Singha, K., Buddhakulsomsiri, J. \& Parthanadee, P., 2017, 'Mathematical model of (', ') inventory policy under limited storage space for continuous and periodic review policies with backlog and lost sales', Hindawi Mathematical Problems in Engineering 2017, 4391970. https://doi.org/10.1155/2017/4391970

Singh, P. \& Twalo, T.G., 2014, 'Effects of poorly implemented performance management systems on the job behavior and performance of employees', International Business \& Economics Research Journal 14(1), 79-94. https://doi.org/10.19030/iber.v14i1.9034

Sobel, M.J. \& Zhang, R., 2001, 'Inventory policies for systems with stochastic and deterministic demand', Operations Research 49(1),157-162.

South Africa, Department of National Treasury, 2009, Inventory management framework 2009, viewed 27 August 2015, from http://www.treasury.gov.za.

Srivastava, S. \& Singh, H., 2017, 'Deterministic inventory model for items with linear demand, variable deterioration and partial backlogging', International Journal of Inventory Research 4(4), 333-349. https://doi.org/10.1504/IJIR.2017.090378

Starman, A.B., 2013, 'The case study as a type of qualitative research', Journal of Contemporary Educational Studies 1(1), 28-43.

Stock, R. \& Lambert, M., 2001, Strategic logistics management, Marketing/Advertising Series, pp. 232-235, Mc Graw Hill, International edn., New York, NY.

Stop Stockout National Survey, 2013, Stock outs in South Africa: A national crisis, viewed 27 August 2015, from http://www.sahivsoc.org.

Tagaras, G. \& Vlachos, D.A., 2001, 'Periodic review inventory system with emergency replenishments', Management Science 47(3), 415-429. https://doi.org/10.1287/ mnsc.47.3.415.9770

Taha, H., 2007, Operation Research: An introduction, 8th edn., pp.427-449, Pearson, Hoboken, NJ.

The American University, 2017, Property inventory \& warehouses control policies and procedures, Internal document. viewed 12 October 2017, from http://documents.aucegypt.edu

Transnet SOC LTD, 2010, Transnet freight rail policy and procedure: Inventory, Internal document.

Tyler, T.R., 2005, 'Promoting employee policy adherence and rule following in work settings: The value of self-regulatory approaches', Law and Society Review 70, 1287-1312.

Wagner, D., Kawulich, B. \& Garner, M., 2012, Doing social research: A global context, 1st edn., McGraw-Hill, London.

Wang, T. \& Toktay, B., 2008, 'Inventory management with advance demand information and flexible delivery', Management Science 54(4), 716-732. https:// doi.org/10.1287/mnsc.1070.0831

Yin, R.K., 2011, Case study research: Design and methods, 5th edn., Sage, Los Angeles, CA. 